\title{
Einige neue Homopteren-Arten und -Varietäten aus Dalmatien und dem Küstenlande.
}

\author{
Von Dr. L. Melichar in Wien.
}

1. Deltocephalus reductus nov. sp.

Scheitel, Vorderhälfte des Pronotum und Schildchen gelblichweiss, Hinterhälfte des Pronotum und Flügeldecken graulichweiss. Scheitel so lang als zwischen den Augen breit, flach, auf der Spitze zwei nach hinten divergirende kurze Striche, dahinter zwei Querflecke, von deren äusserem Ende ein feiner kurzer Ast nach vorn zieht, im Nacken zwei vom Vorderrande des Pronotum zum Theile gedeckte Flecken, schwarz. In der Mitte des Scheitels eine feine vertiefte Längslinie, welche jedoch die Scheitelspitze nicht erreicht. Stirn bräunlich, mit weissen Querstreifen beiderseits und weisser Mittellinie. Wangen, Zügel und Clypeus hell gelblich. Auf der Mitte der Wagenzügelnaht ein brauner Punkt, ein kleinerer (häufig fehlender) auf der oberen Hälfte der gedachten Naht. In der Mitte des Clypeus ein brauner Strich, die Spitze des kurzen Schnabels braun. Beim o ist die dunkle Zeichnung des Gesichtes häufig sehr undeutlich, fehlt zuweilen ganz. Pronotum doppelt so breit als lang, auf der Scheibe eine nach vorn bogige, vertiefte Querlinie, an deren Enden sich je ein schwarzer Fleck befindet. In den Grundwinkeln des Schildchens ein schwarzer dreieckiger Fleck, welcher jedoch zumeist vom Hinterrande des Pronotum verdeckt wird; vor der Schildchenspitze eine feine Querlinie. Die graulichweissen Flügeldecken bedecken nicht die Hinterleibsspitze, sind hinten abgerundet, die Apicalzellen kurz. Die Deckennerven hellweiss, die zum Aussenrande verlautenden Quernerven, sowie die Enden der Clavusnerven auf erweiterten weissen Stellen. Sämmtliche Nerven sind schwarzbraun gesäumt, die Umsäumung in den Zellenecken bedeutend stärker und deutlicher, sehr häufig in punktförmige Flecke aufgelöst, und bis auf drei fast constant vorkommende Flecke erloschen, u. zw. ein Fleck im Clavus an dem zur Corium-Clavusnaht laufenden Quernerven, ein zweiter in der oberen Ecke der inneren Discoidalzelle und der dritte in der unteren Ecke der inneren Anteapicalzelle. Der Hinter- 
leib oben am Grunde schwarz, die Spitze hellgelblich, Bauch braun bis schwarzbraun, die Hinterränder schmal, die Seiten breiter gelblich gefärbt. Beim o ist der Bauch sowie die ganze Unterseite mehr oder weniger hell gefärbt, bloss der Bauchgrund dunkel verfärbt. Beine graulichweiss, mit braunen Flecken an den Schenkeln und braunen Punkten an der Basis der Schienendornen.

07. Genitalklappe doppelt so lang als das vorletzte Bauchsegment, lappenförmig gerundet, an den Seiten leicht geschweift, an der Basis schwarzbraun; selten ist die Klappe ganz schwarzbraun, weiss gerandet. Die Genitalplatten um die Hälfte länger als die Genitalklappe, aneinanderschliessend, am Ende einzeln abgerundet, schief nach oben gerichtet, an den Aussenseiten etwas gebuchtet und mit steifen Borsten besetzt. Der zusammenschliessende innere Rand derselben ist stets, selbst bei den hellsten Exemplaren, breit schwarzbraun bis schwarz gefärbt. Das Rückensegment gelblich, um die Afterröhre leicht ausgebuchtet, die Seitenlappen mit abstehenden gelbbraunen Borsten besetzt.

q. Letztes Bauchsegment über doppelt so lang als das vorhergehende, der Hinterrand mit zwei seichten Einbuchtungen, welche einen kleinen, runden und flachen Mittellappen einschliessen; die Seitenecken weiter nach hinten vorstehend, gerundet. Auf der Mitte des Hinterrandes ein schwarzbrauner Fleck. Die Scheidenpolster braun gefleckt und mit gelben Borsten besetzt.

Länge: $\sigma^{\top}$ \& $2-21 / \mathrm{sm}$.

Dalmatien (Ragusa), auf Grasplätzen im Juli gesammelt.

Diese in der Umgebung von Ragusa nicht seltene Art steht dem D. multinotatus Boh. sehr nahe, ist jedoch im Vergleiche mit dem letztgenannten auffallend kleiner und schlanker, der Scheitel weniger spitzig vorgezogen und insbesondere durch die Form der Genitalsegmente von D. multinotatus Boh verschieden Beim letztgenannten ist beim $\delta$ die Genitalklappe mehr dreieckig, mit fast geraden Seiten, die Genitalplatten stets einfärbig; beim $\subsetneq$ ist der Lappen sehr flach, die Seitenecken des letzten Bauchsegmentes deutlich eckig. D. multinotatus Boh. ist schon beim ersten Anblicke durch die hell gelblichröthliche Färbung zu erkennen, während bei der vorliegenden südlichen Art die graulichweisse Färbung vorherrscht. Vœn D. Bellevoyei Put. unterscheidet sich diese Art durch breitere Gestalt und andcre Zeichnung der Flügeldecken. Ich glaube daher mit Recht diese südliche Art als eine neue Art anführen zu können. 


\section{Liburnia stigmatica nov. sp.}

Stirn fast dreimal so lang als zwischen den Augen breit, gelblich. Die Seiten der Stirn fast gerade, zı m Clypeus etwas convergirend; die Stirnkiele tadenförmig, bei schiefer Ansicht deutlicher, der Mittelkiel auf dem abgerundeten Uebergange der Stirn zum Scheitel erloschen; ie beiden Nackensrübchen deutlich; Fühler gelblichbraun. Das Pronotum und Schildchen gelblichbraun, bei langgeflügelten Formen häufig schwarzbraun, die Kiele deutlich. Die verkürzten Flügeldecken nur ${ }^{2 / 3}$ des Hinterleibes bedeckend, durchscheinend, hinten gerundet, die gelblichen Nerven fein punktirt. Die entwickelten Flïgeldecken glashell, durchsichtig, länger als der Hinterleib, die Nerven gelblich, fein punktirt, die Endnerven etwas dunkler, am Aussenrande der Membran ein länglicher, den ganzen Raum der ersten Apicalzelle einnehmender schwarzbrauner Fleck. Der Hinterleib beim $\sigma$ ganz schwarz oder schwarz mit gelben Flecken in der Mitte des Rückens; beim $q$ ist der Hinterleib gelbbraun, an den Seiten mit dunklen, zusammenfliessenden Flecken. Die Brust gelblichbraun, an den Seiten der Mittelbrust jederseits ein runder schwarzer Fleck. Bauch gelbbraun, mit schwarzen Flecken. Beine gelbbraun.

$0^{7}$. Genitalsegment fast doppelt so lang als das vorhergehende Rückensegment, cylindrisch, schwarz, der obere Rand von der Seite gesehen mit dem unteren Rande eine nach hinten ragende stumpfe Ecke bildend, un das Afterrohr bis zur Mitte des Segmentes ausgeschnitten, die Ecken des Ausschnittes spitzig, nach innen und unten gerichtet. Der Unterrand wenig tief ausgeschnitten, gelblich. Der Jmfang des Genitalsegmentes von hinten gesehen rundlich. Die Griffel kräftig, gelb- bis schwarzbraun, bis zum Afterrohr reichend; von der Seite gesehen leicht gebogen, gleichbreit, oben gestutzt, die hintere obere licke in einen nach vorn gekrümmten, starken Zahn verlängert. An der Basis der Griffel befindet sich auf der Innenseite derselben ein bis fast zur Mitte der Genitalöffnung reichender, mit der convexen Seite nach innen zugekehrter, gekrïmmter Zahn.

q. Die Genitalplatten kurz, einander sich nicht berührend, die Scheidenpolster gelbbraun.

Länge: $\sigma^{7} \rho^{1 /} 2^{1 / 3} \mathrm{~mm}$, mit entwick. Flügeldecken $3_{13}^{1 /} \mathrm{mm}$. Ragusa (Dalmatien), im Juli auf trockenen Grasplätzen. 
Diese Art ist durch die Form des Genital-Apparates, insbesondere durch die Gestalt der Griffel beim $\sigma^{\nearrow}$ charakterisirt. Die langgeflügelten Formen sind überdies durch den schwarzbrauuen Fleck am Aussenrande der Membran der Flügeldecken gekennzeichnet.

\section{Doratura paludosa nov. sp.}

Von den bisher bekannten zwei Arten D. stylata Boh. und homophyla Flor durch den etwas längeren Scheitel ausgezeichnet, welcher fast so lang ist als zwischen den Augen breit. Am Vorderrande des Scheitels befinden sich drei schwarze Flecken, von welchen der mittlere, an der Scheitelspitze stehende grössere Fleck sich häufig bis zum Scheitelhinterrande verlängert. Stirn mit den gewöhnlichen zwei schwarzen Querbinden ( $\left.\sigma^{7}\right)$, welche häufig in Flecken aufgelöst erscheinen (q). Die Flügeldecken zusammen breiter als jede für sich lang, fein punktirt, mit undeutlichen Nerven. Hinterleib oben mit 6 aus schwarzen Punkten und Atomen zusammengesetzten Längsstreifen, von welchen die zwei inneren, eine weisse Mittellinie einschliessend, dicht neben einander verlaufen; zwischen dem zweiten und dritten Längsstreifen jeder Seite eine Reihe von Punkten. Die Unterseite des Abdomens schwarz, mit schmal gelben Hinterrändern, die Vorderecken der Bauchsegmente gelb $\left(\sigma^{\top}\right)$ oder gelbbraun, mit einem schwarzen Fleck in der Mitte des Hinterleibsgrundes (q). Beine mit schwarzen Flecken und Atomen.

$\sigma^{7}$. Genitalklappe klein, aber deutlich als schmaler Saum in der Mitte des letzten Bauchsegmentes vorragend, die Genitalplatten so lang als an der Basis breit, aneinanderschliessend, hinten einzel! abgerundet, an den Seiten am Grunde le:cht gebuchtet; das letzte Rückensegment kaum länger als die Genitalplatten von der Seite gesehen, mit geradem Hinterrande, welcher mit dem Unterrande eine stumpfe Ecke bildet, oben um das Afterrohr leicht gebuchtet und mit einem schwarzen Punkt und cinem Querfleck jederseits.

․ Letztes Bauchsegment in der Mitte kürzer als an den Seiten; in der Mitte des Hinterrandes eine kleine rundliche Einbuchtung, die Seitenecken stumpf. Legescheide mit ihrem dritte.i Theil vorragend, das Rückensegment hinten ausgebuchtet, dessen Seiten mit stumpfer Spitze nach hinten vorstehend. Auf der Mitte des Rückensegmentes ein schwarzer Längsstrich.

Länge: $\sigma^{7} 3-3^{1 / 3}$, \& $4 \quad 4^{1 / 2} \mathrm{~mm}$.

Auf sumpfigen Stellen bei Monfalcone (Küstenland), im Juli. 
Diese Art ist durch die kleinere und gedrungenere Gestalt, durch den etwas längeren Scheitel und insbesondere durch die Form der Genitalsegmente von den beiden obgenannten Arten verschieden. Auch die Lebensweise dieser Art ist eine von jener der beiden bekannten verschieden. Während $\nu$. stylata und homophyla sich vorzugsweise auf dürren sunnigen Stellen aufhalten, bewohnt diese feuchte, sumpfige Grasplätze.

\section{Zygina versuta nov. sp.}

Gelblichweiss, Scheitel um 1/4 kürzer als das Pronotum, vorn gerundet, gelblichweiss, in der Mitte citronengelb, mit zwei schwarzen, runden Punkten an der scheitelspitze und einer kurzen, feinen, vertietten Längslinie im Nacken. Die Scheitelpunkte sind einander näher als jeder vom inneren Augenrande gestellt; Stirn länglich, im oberen Theile gelblich mit zwei ziemlich grossen, nierenförmigen weissen Flecken, welche mit ihrer Convexität gegen die Mittellinie gestellt sind. Die Stirn im unteren Theile gelblichweiss, mit undeutlichen Querstreifen an den Seiten und weisser Mittelinie in der Mitte. Clypeus schwarz, Wangen und Fühler weiss. Pronotum gelblichweiss. In der Mitte des vorderen Drittels zwei schwarze kleine Punkte, welche im Vergleiche mit den Scheitelpunkten kleiner und quergestellt sind und von einander nur wenig weiter entfernt sind als erstere. An den Seiten des Pronotum mehr nach rückwärts zwei kleine schwarze Eleckchen. Schildchen gelblichweiss, Spitze gelblich, in den Grundwinkeln jederseits ein grosses schwarzes Dreieck, welches zum Theile vom Hinterrande des Pronotum bedeckt ist. Vor der Schildchenspitze eine kurze vertiefte Querlinie. Die Decken glashell, durchsichtig, im Clavus ein gelblicher Längsstreif längs der Clavus-Coriumnaht, im Corium ein ähnlicher Längsstreif. Die Nerven zart, gelb; die Membran rauchbraum, Flügel hell, durchsichtig, Brust gelblichweiss, nur die Seiten der Mittelbrust, der Hinterleibsrücken, mit Ausnahme der schmalen Segmentränder und der Hinterleibsspitze, und die Legescheide schwarz. Bauch und Beine gelblichweiss, die Hinterschienen ohne schwarze Punkte, mit gelblichen Borsten besetzt. Tarsen gelblichweiss, Klauen schwarz. Länge: o $2^{1 / 2} \mathrm{~mm}$.

Ragusa (Dalmatien), im August von Quercus abgeklopft.

Der $Z$. parvula Boh. nahestehend, jedoch von derselben durch die helle Grundfarbe, die gelben Streifen auf den Flügeldecken, die glashellen durchsichtigen F'lügel und die gelblich gefärbte Unterseite verschieden. Bei $Z$ par- 
vula Boh ist die Grundfarbe mehr oder weniger röthlich-gelb, die Flügeldecken sind dunkel gezeichnet, die Flügel rauchbraun und die Unterseite wie die Oberseite des Abdomen stets schwarz.

5. Lepyronia coleopterata L. var. obscura nov. var бౌ.

Bei Monfalcone (Küstenland) fand ich zwei Männchen der im Süden sehr häufig vorkommenden Lepyronia coleopterata, welche durch ihre gleichmässige, schwarzbraune lärbung des Scheitels, Pronotıms und der Flügeldecken, sowie durch dichtes kurzes, anliegendes Toment der Oberfläche von der typischen Form abweichen.

6. Dictyophora europaea L. var. rosea nov. var.

Von der hellgrün gefärbten Stammart nur durch die Färbung verschieden. Der Körper, die Beine und das Geäder der Flïgel sind schön hellkarminroth gefärbt, welche Farbe auch nach dem Abtödten und Trocknen des Thieres unverändert bleibt. Ich fand drei Exemplare dieser Varietät bei Ragusa in Dalmatien. Die Larven dieser Varietät zeigen gleichfalls eine blassrothe oder schmutzigrothe Färbung, während die Larven der gewöhnlichen grünen Stammform blassgrün oder schmutziggrün gefärbt sind.

\section{Neue Carabiciden.}

\section{Von k. k. Sanitätsrath Dr. A. Fleischer in Brünn.}

\section{Amara harpaloides $m$.}

Hinterecken des Halsschildes vollkommen verrundet, Fortsatz der Vorderbrust an der Spitze gerandet, Episternen der Hinterbrust nicht punktirt, Mittelschienen des $\sigma^{7}$ innen nicht gezähnt, Hinterschienen des $\sigma^{\top}$ innen nicht behaart:

\section{nov. subgen. Cyclothorax m.}

Dem allgemeinen Habitus nach bei oberflächlicher Betrachtung einem Harpalus, speciell dem gleichgrossen laevicollis Schaum. ähnlich; durch das tribuelle Merkmal - nur drei erweiterte Vordertarsen beim $\sigma^{7}$ - von den Harpaliden, ebenso wie durch das eiförmige, zugespitzte Endeglied der Lippentaster von den Pterostichiden sicher zu unterseheiden und als zum Genus „Amara" gehörig erkennbar. - In der Reihe der Untergattungen reiht sich das Subg. Cyclothorax unmittelbar an Leironotus Ganglb. an, von welcher Untergattung sich Cyclothorax hauptsächlich durch den deutlich gerundeten Fortsatz der Vorderbrust unterscheidet. 


\section{$2 \mathrm{BHL}$ Biodiversity Heritage Library}

Melichar, Leopold. 1897. "Einige neue Homopteren-Arten und -Varietäten aus Dalmatien und dem Küstenlande." Wiener entomologische Zeitung 16, 67-72. https://doi.org/10.5962/bhl.part.12835.

View This Item Online: https://www.biodiversitylibrary.org/item/44053

DOI: https://doi.org/10.5962/bhl.part.12835

Permalink: https://www.biodiversitylibrary.org/partpdf/12835

\section{Holding Institution}

Smithsonian Libraries

\section{Sponsored by}

Smithsonian

\section{Copyright \& Reuse}

Copyright Status: NOT_IN_COPYRIGHT

This document was created from content at the Biodiversity Heritage Library, the world's largest open access digital library for biodiversity literature and archives. Visit BHL at https://www.biodiversitylibrary.org. 